\title{
Identification and Determination of Phenolic Compounds in Rapeseed Meals (Brassica napus L.)
}

\author{
Si-Chang Yang1, Mariadhas Valan Arasu ${ }^{2}$, Jin-Hyuk Chun ${ }^{1}$, \\ Young-Seok Jang', Yong-Hwa Lee ${ }^{3}$, In Ho Kim4, Ki-Taek Lees, \\ Soon-Taek Hong 5 , Sun-Ju Kim ${ }^{{ }^{*}}$ \\ ${ }^{1}$ Bio-Environmental and Chemistry, Chungnam National University, Daejeon, Republic of Korea \\ ${ }^{2}$ Department of Botany and Microbiology, Addiriyah Chair for Environmental Studies, College of Science, King \\ Saud University, Riyadh, Saudi Arabia \\ ${ }^{3}$ Bio-Energy Crop Center, National Institute of Food Science, Rural Development Administration, Muan-County, \\ Republic of Korea \\ ${ }^{4}$ Department of Animal Resource \& Science, Dankook University, Cheonan-Si, \\ Republic of Korea \\ ${ }^{5}$ Food Science and Technology, Chungnam National University, Daejeon, Republic of Korea \\ Email: ${ }^{*}$ kimsunju@cnu.ac.kr
}

Received 6 January 2015; accepted 23 January 2015; published 29 January 2015

Copyright (C) 2015 by authors and Scientific Research Publishing Inc.

This work is licensed under the Creative Commons Attribution International License (CC BY). http://creativecommons.org/licenses/by/4.0/

\section{Abstract}

This study aimed in the identification and quantification of phenolic compounds in different four varieties of rapeseeds (Brassica napus L.) using LC-MS and HPLC. LC-MS analysis guided to identify 12 phenolic compounds including sinapine, sinapine(4-O-8')guaiacyl, feruloyl choline(4-0-8') guaiacyl, kaempferol-3- $O$-sinapoyl-sophoroside-7- $O$-glucoside, kaempferol-3- $O$ - $\beta$-sophoroside, cyclic spermidine-alkaloid, feruloyl choline(5-8')guaiacyl, kaempferol-sinapoyl-trihexoside,1,2-di$O$-sinapoyl-gentiobiose, 1,2-di-O-sinapoyl-glucose, feruloyl choline(4-0-8')guaiacyl-di-sinapoyl, and sinapine(4-0-8')guaiacyl-di-sinapoyl, respectively. Total phenolic compounds in rapeseed meals were ranged from 38.50 (2012 "Sunmang") to $63.95 \mathrm{mg} / \mathrm{g}$ dry weight (DW) (2014 Jeju local cultivar). Main phenolic compositions were cyclic spermidine-alkaloid, kaempferol, feruloyl choline, and sinapine. Sinapine was predominant compound among all the samples ranged from 29.74 to $52.24 \mathrm{mg} / \mathrm{g}$ DW (mean $\mathbf{7 9 \%}$ of total phenolic contents). This study provided the information for the variation of phenolic compounds between the varieties of rapeseeds and the cultivation periods. Furthermore, this information can be developed for bio-energy industry as a reducer of the cost of the bio-energy products.

\footnotetext{
*Corresponding author.
}

How to cite this paper: Yang, S.-C., Arasu, M.V., Chun, J.-H., Jang, Y.-S., Lee, Y.-H., Kim, I.H., Lee, K.-T., Hong, S.-T. and Kim, S.-J. (2015) Identification and Determination of Phenolic Compounds in Rapeseed Meals (Brassica napus L.). Journal of Agricultural Chemistry and Environment, 4, 14-23. http://dx.doi.org/10.4236/jacen.2015.41002 


\section{Keywords}

\section{LC-MS Analysis, HPLC Analysis, Rapeseed Meal, Phenolic Compounds}

\section{Introduction}

Rapeseed (B. napus L.) is one of Brassica vegetables, produced in many countries such as Australia, Canada, China, Europe, India, the Russian Federation, and the United States [1]. Rapeseed production amount in the world market is highest in China (11,760 ton, 35.7\%) and EU (11,384 ton, 34.6\%) [2]. Rapeseed has been used for landscape plant because of its distinct yellow flowers. Recently, however, it is mainly cultivated for its oil which is used for bio diesel or bio ethanol. Rapeseed is one of the main materials of bio-diesel (83\%) and utilizations of residues of rapeseed such as rapeseed meal, stem and flower also have been interested by oilseed industries in order to reduce the production expenses [3]. There is a lot of utilization of rapeseed residues due to their high nutritive value and functional compounds such as amino acids, carotenoids, flavonoids, and glucosinolates [4]. Thus, rapeseed meals have been used for organic fertilizer, feed stuff for livestock, adhesive hydrolyzed by enzymes [5].

Functional compounds among other compounds of rapeseed residues are phenolics in rapeseed meal, which this study focused on. Flavonoids belonged to phenolic compositions are polyphenols which have $\mathrm{C}_{6} \mathrm{C}_{3} \mathrm{C}_{6}$ skeletons. They are a large family of secondary plant metabolites contained anti-oxidation, anti-inflammation, antiallergic effects, etc. [6]. Cartea et al. (2011) identified that $p$-coumaric, sinapic and ferulic acids, and main flavonoids are kaempferol, quercetin, and cyanidin from the leaves and roots of rapeseed meal but not on the seeds or meals [7]. On the other hand, Oskoueian et al. (2011) reported other phenolic acids such as (gallic and syringic acids) and flavonoids (apigenin, kaempferol, naringenin) in rapeseed meal [8]. These identified phenolic compounds have organic acids and sugar moiety in their chemical structure. These sugar moieties have significant influence on the identification and quantification of the phenolic compounds by analytical methods. However, the phenolic compounds with aglycone moiety were acid hydrolyzed to eliminate the sugar in order to compare and quantify the exact phenolic compounds [8] [9]. In this study, analytical methods were established to identify and quantify the phenolic compounds present in rapeseed meal.

\section{Materials and Methods}

\subsection{Chemical Reagents}

The HPLC-grade methanol was obtained from J. T. Baker Chemical Co. (Phillipsburg, NJ, USA). Tert-Butyl hydroquinone (TBHQ) was obtained from Alfa Aesar (Heysham, Lancashire, UK) and hydrochloric acid was purchased from Wako Pure Chemical Industries, Ltd. (Osaka, Japan). Sinapine was purchased from Chem. Faces (Wuhan, China) and kaempferol was purchased from Wako, Japan. Ultra-pure water used in this study was made by PURE LAB Option-Q system (ELGA Lab Water, VWS Ltd., UK).

\subsection{Plant Materials}

Two types of rapeseeds cultivated in Jeju Island (Jeju local cultivar) and Muan (“Sunmang”) were annually provided from 2011 to 2013 by the Bio-Energy Crop Center, National Institute of Food Science (Muan, Korea). The Jeju local cultivar was cultivated from October to May, whereas "Sunmang" was grown from October to June. After rapeseeds were harvested and de-oiled, the residue, rapeseed meal, were provided to chemical analyzes for phenolic compositions. In 2014, imported rapeseed meal from India was obtained from the Department of Animal Resource and Science, Dankook University.

\subsection{Extraction of Phenolic Compounds}

Extraction of phenolic compositions was performed following the standard method with slight modifications [10]. Rapeseed meal (dried powder $100 \mathrm{mg}$ ) was mixed thoroughly with $1 \mathrm{~mL}$ of $10 \%$ methanol contained $0.1 \%$ phosphoric acid and vortexed for $10 \mathrm{~min}$. After that, the extract solution was incubated for $3 \mathrm{~h}$ at $37^{\circ} \mathrm{C}$ with vor- 
texing every hour. Subsequently, it was centrifuged at $12,000 \mathrm{rpm}$ at $4^{\circ} \mathrm{C}$ for $10 \mathrm{~min}$. The supernatant was filtered through PTFE hydrophilic syringe filter $(0.45 \mu \mathrm{m}$ pore size, $13 \mathrm{~mm}$ diameter $)$ prior to the quantification in HPLC.

\subsection{LC-ESI-MS Analysis}

Each peak of rapeseed meal separated using HPLC (Perkin Elmer Flexar, USA) for accurate LC-MS analysis was analyzed by 4000 Qtrap LC-MS/MS system. Mass analysis was carried out with $1.0 \mathrm{~mL} / \mathrm{min}$ flow rate and positive ion mode. The UV spectrum was performed at 280 and $350 \mathrm{~nm}$. The mobile phase consisted of (A) MeOH: water: acetic acid [5:92.5:2.5, (v/v/v)] + 0.01\% TFA and (B) MeOH: water: acetic acid [95:2.5:2.5, $(\mathrm{v} / \mathrm{v} / \mathrm{v})]+0.01 \%$ TFA. The binary gradient used was as follows: 5\% - 100\% (0 - $13 \mathrm{~min})$. The binary gradients were used as follows: 0 - $10 \mathrm{~min}, 0 \%$ - 20\% B; 10 - $15 \mathrm{~min}, 20 \%-40 \% \mathrm{~B} ; 15$ - $20 \mathrm{~min}, 40 \% \mathrm{~B} ; 20-25 \mathrm{~min}$, $40 \%$ - 50\% B; 25 - 28 min, 50\% B; 28 - 30 min, 50\% - 0\% B; 30 - 40 min, 0\% B.

\subsection{HPLC Analysis}

Phenolic compounds in rapeseed meal were analyzed by Perkin Elmer Flexar (USA). Samples were separated on a Capcell PAK C18 column $(4.6 \times 250 \mathrm{~mm}, 5 \mu \mathrm{m}$ particle size; Shiseido, Tokyo, Japan $)$ maintained at $40^{\circ} \mathrm{C}$. The flow rate was $1.0 \mathrm{~mL} / \mathrm{min}$, and the injection volume was $10 \mu \mathrm{L}$. The mobile phase consisted of $(\mathrm{A}) \mathrm{MeOH}$ : water: acetic acid (5:92.5:2.5, v/v/v) and (B): water: acetic acid (95:2.5:2.5, v/v/v). Additionally, tri-floro acetic acid (TFA) was added in order to improve the peak separations. These gradients were used as follows: 0-10 min, 0\% - 20\% B; 10 - 15 min, 20\% - 40\% B; 15 - 20 min, 40\% B; 20 - 25 min, 40\% - 50\% B; 25 - 28 min, $50 \%$ B; 28 - $30 \mathrm{~min}, 50 \%$ - 0\% B; 30 - $40 \mathrm{~min}, 0 \% \mathrm{~B}$. The absorbance was measured at 280 and 350 nm. Identification in the peaks of HPLC chromatogram of the phenolic compounds was based on spectra, standards, and literature data. External standards were used for identification and quantification, and results are presented as milligram per gram of dry weight [10].

\subsection{Acid Hydrolysis}

Acid hydrolysis procedures were done to indentify the unknown phenolic compounds. Phenolic compounds usually conjugated with sugars and organic acids were extracted by acid hydrolysis through two extraction methods (Extraction I and II) in order to eliminate the glycoside. The difference between extraction I and II was the time of adding acid into the extractions. In the Extraction I, 10\% methanol contained 0.1\% phosphoric acid, TBHQ (2 g/L), and $0.25 \mathrm{ml}$ of $6 \mathrm{M}$ hydrochloric acid was orderly added into $2.0 \mathrm{ml}$ Eppendorf-tube containing rapeseed meal (100 mg), and then the mixture was extracted with vortexing for $10 \mathrm{~min}$ [11]. On the other hand, in the Extraction II, rapeseed meal was extracted with adding of $10 \%$ methanol contained $0.1 \%$ phosphoric acid together with TBHQ. And hydrochloric acid was then added with different ratios $(1: 1,1: 2,1: 3$, v/v; labeled as EII-A, EII-B, EII-C, respectively) [12]. After each extraction process, the mixtures were centrifuged at 12,000 rpm at $4^{\circ} \mathrm{C}$ for $15 \mathrm{~min}$. Finally, the extracts were passed through a $0.45 \mu \mathrm{m}$ PTFE ACRODISC CR13 hydrophilic syringe filter before HPLC analysis.

\section{Results and Discussion}

\subsection{Identification of Phenolic Compounds by LC-ESI-MS Analysis}

Phenolic compounds were identified with range of 8.69 - 19.84 retention times (RT) in total ion chromatogram, TIC (Figure 1). The RT is not matched exactly with Figure 2 and Figure 3 because HPLC analysis was performed with different company of analysis instrument. In addition, LC-MS was the first step in this research. The analytical method, especially entire time of the analysis, was modified reasonably after LC-MS process. The identified phenolic compounds including systematic and common names and the principal ions are listed in Table 1. Twelve phenolic and two unknown compounds were detected in all rapeseed meal extracts. Each compounds was identified from their protonated molecular ions $[\mathrm{M}+\mathrm{H}]^{+}$and one main productions, corresponding to the adducts $[\mathrm{M}+\mathrm{Na}]^{+}$, compared to the literature information. The phenolic compounds namely [sinapine, sinapine (4-O-8')guaiacyl, feruloyl choline(4-O-8')guaiacyl, kaempferol-3-O-sinapoyl-sophoroside-7-O-glucoside, kaempferol-3-O- $\beta$-sophoroside, unknown-1, cyclic spermidine-alkaloid, feruloyl choline(5-8')guaiacyl, kaemp- 


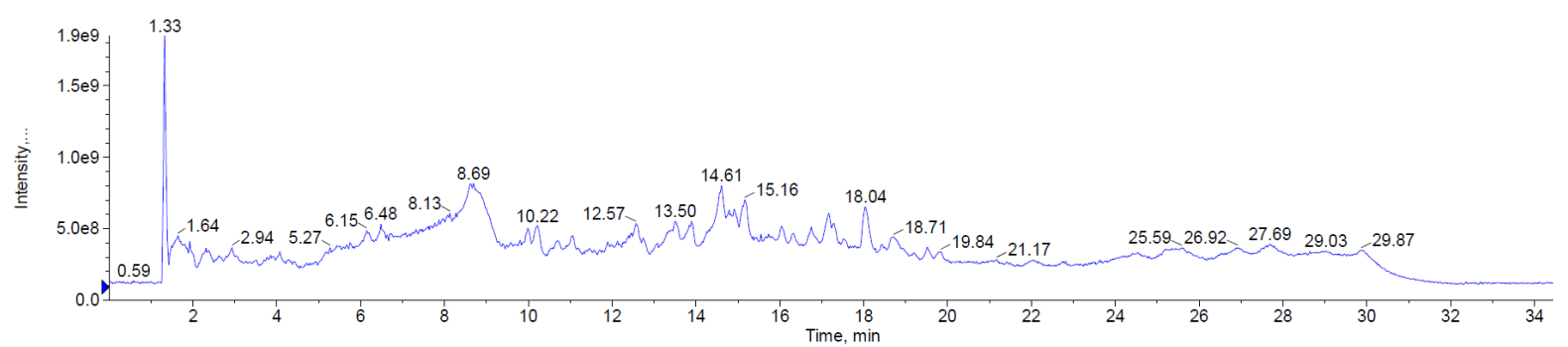

Note: because LC-MS analysis was first step in this study, the retention time (RT.) of this TIC is not matched exactly with fig.1 and 2. RT. 8.69 is the sinapine in this TIC.

Figure 1. Total ion chromatogram (TIC) of phenolic compounds in rapeseed meal.
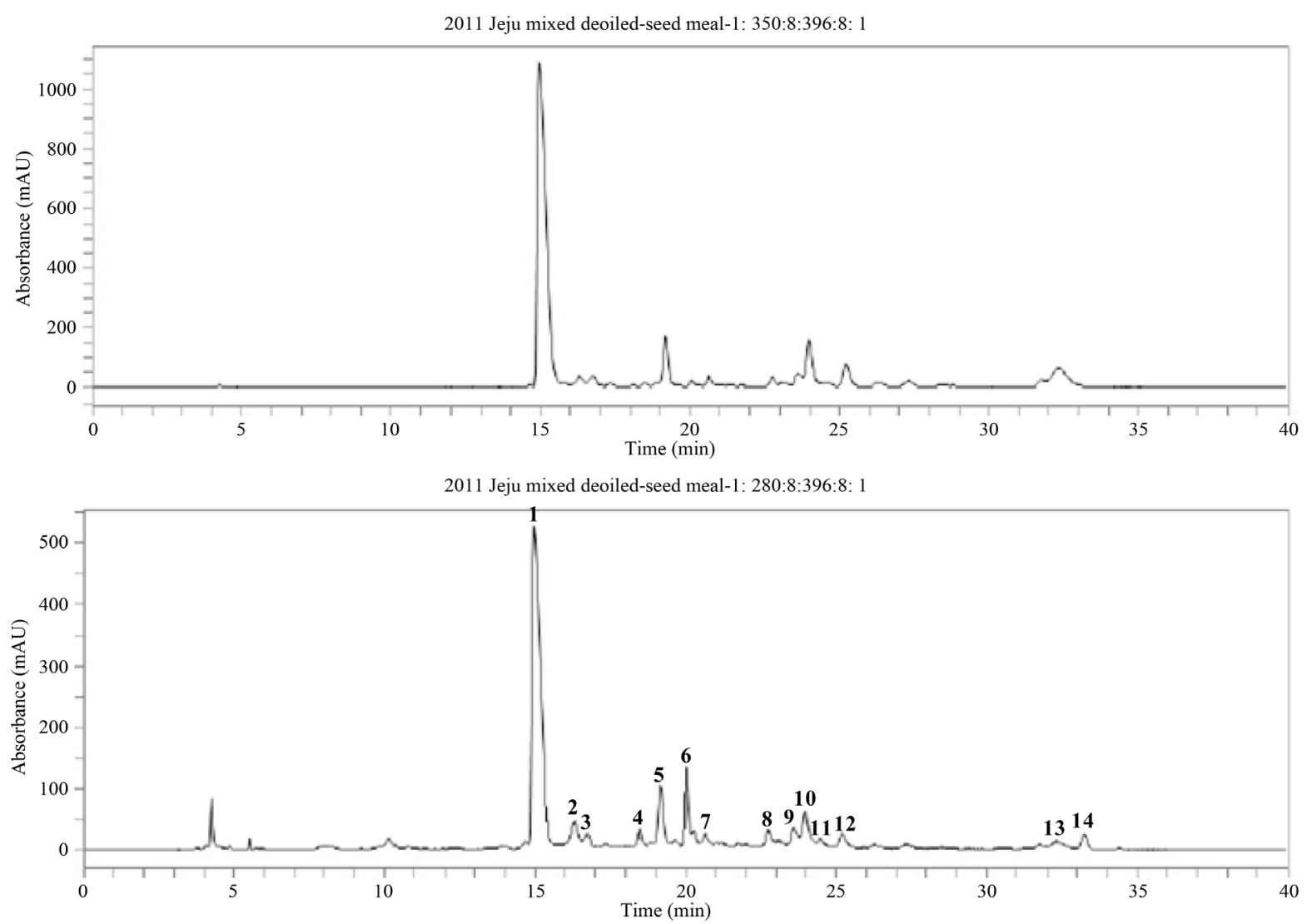

Figure 2. HPLC chromatogram of phenolic compounds in 2011 center meal (peak 13 was not detected in center meal).

ferol-sinapoyl-trihexoside, 1,2-di-O-sinapoylgentiobiose, 1,2-di-O-sinapoylglucose, feruloyl choline(4-O-8') guaiacyl-di-sinapoyl, unknown-2, and sinapine(4-O-8')guaiacyl-di-sinapoyl] were identified based on fragmentation patterns of MS spectra and quantified based on the peak areas of HPLC chromatogram (Figure 2 and Figure 3). MS data revealed that the main phenolic compounds (sinapine, kaempferol, feruloyl choline and cyclic spermidine-alkaloid) were conjugated with sugar such as glucose, sophorside, tri-hexoside, and guaiacyl. The HPLC peaks 1, 2, 4, 9, 10, 11, 12 and 14 have sinapoyl moiety derived from sinapine (sinapoyl choline; $[\mathrm{M}+\mathrm{H}]^{+}$, $\mathrm{m} / \mathrm{z}$ 310), whereas, peaks 4,5 , and 9 have kaempferol $\left([\mathrm{M}+\mathrm{H}]^{+}, \mathrm{m} / \mathrm{z} 287\right)$. Peak 4 and 5 were identified as kaempferol-3-O-sinapoyl-sopohoroside-7-O-glucoside and kaempferol-3-O- $\beta$-sophoroside. Even though the two compounds were similar in structure, the mass spectra represented the difference in clear fragments. Their mass values $(\mathrm{m} / \mathrm{z})$ were detected at 979 in peak 4 and at 611 in peak 5 [13], respectively. On the other hand, feruloyl choline and cyclic spermidine-alkaloid need to acid hydrolysis because of their molecular weights were not included in MS spectra library. Peaks 3, 8 and 12 were confirmed as feruloyl-choline and peak 7 has cyclic spermidine-alkaloid respectively. MS spectra of unknown-1 and 2 (peak 6 and 13) were similar to kaempferol compounds 
Table 1. Identification of phenolics and their mass spectra in rapeseed meals.

\begin{tabular}{|c|c|c|c|c|c|}
\hline No. ${ }^{a}$ & Trivial names & $\begin{array}{c}\text { Molecular } \\
\text { weight }\end{array}$ & {$[\mathrm{M}+\mathrm{H}]^{+}(\mathrm{m} / \mathrm{z})$} & MS/MS $(m / z)$ & References \\
\hline 1 & Sinapine & 310 & 311 & 251/207/175 & [11] \\
\hline $2^{\mathrm{b}}$ & Sinapine(4-O-8')guaiacyl & 506 & 507 & $310 / 251 / 221 / 207 / 175$ & [13] \\
\hline 3 & Feruloyl choline(4-O-8')guaiacyl & 476 & 477 & 476/417/221/145 & [13] \\
\hline $4^{\mathrm{b}}$ & Kaempferol-3-O-sinapoyl-sopohoroside-7-O-glucoside ${ }^{*}$ & 978 & 979 & 979/611/449/287 & {$[14]$} \\
\hline 5 & Kaempferol-3-O- $\beta$-sophoroside ${ }^{*}$ & 610 & 611 & $611 / 449 / / 287$ & [15] \\
\hline $6^{\mathrm{b}}$ & Unknown-1 & 978 & 979 & 979/817/496/458/207 & \\
\hline 7 & Cyclic spermidin-alkaloid & 496 & 497 & 496/478/408/351/325/251/207/175 & [13] \\
\hline 8 & Feruloyl choline(5-8')guaiacyl & 458 & 459 & 458/399/381/369/207 & [13] \\
\hline 9 & Kaempferol-sinapoyl-trihexoside ${ }^{*}$ & 978 & 979 & 979/817/655/369 & [13] \\
\hline 10 & 1,2-Di-O-sinapoylgentiobiose & 754 & - & 777/531/369/207/175 & {$[16]$} \\
\hline 11 & 1,2-Di-O-sinapoylglucose & 592 & - & $615 / / 391 / 369 / 207 /$ & [13] \\
\hline 12 & Feruloyl choline(4-O-8')guaiacyl-di-sinapoyl & 682 & 683 & 682/623/403/221/207/145 & [13] \\
\hline 13 & Unknown-2 & 838 & 839 & 839/817/682/655/538/369 & \\
\hline 14 & Sinapine(4-O-8')guaiacyl-di-sinapoyl & 712 & 713 & 712/653/207/179/175/147 & [13] \\
\hline
\end{tabular}

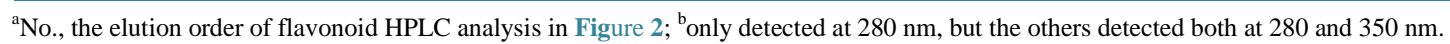

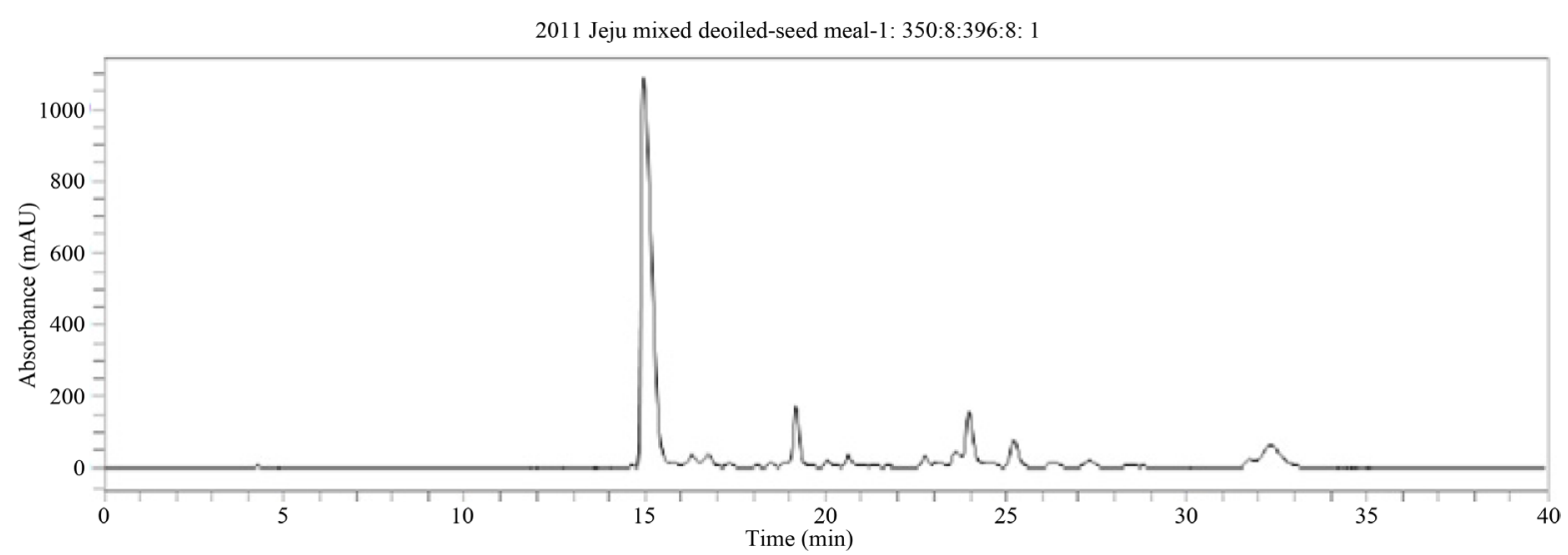

2011 Jeju mixed deoiled-seed meal-1: 280:8:396:8: 1

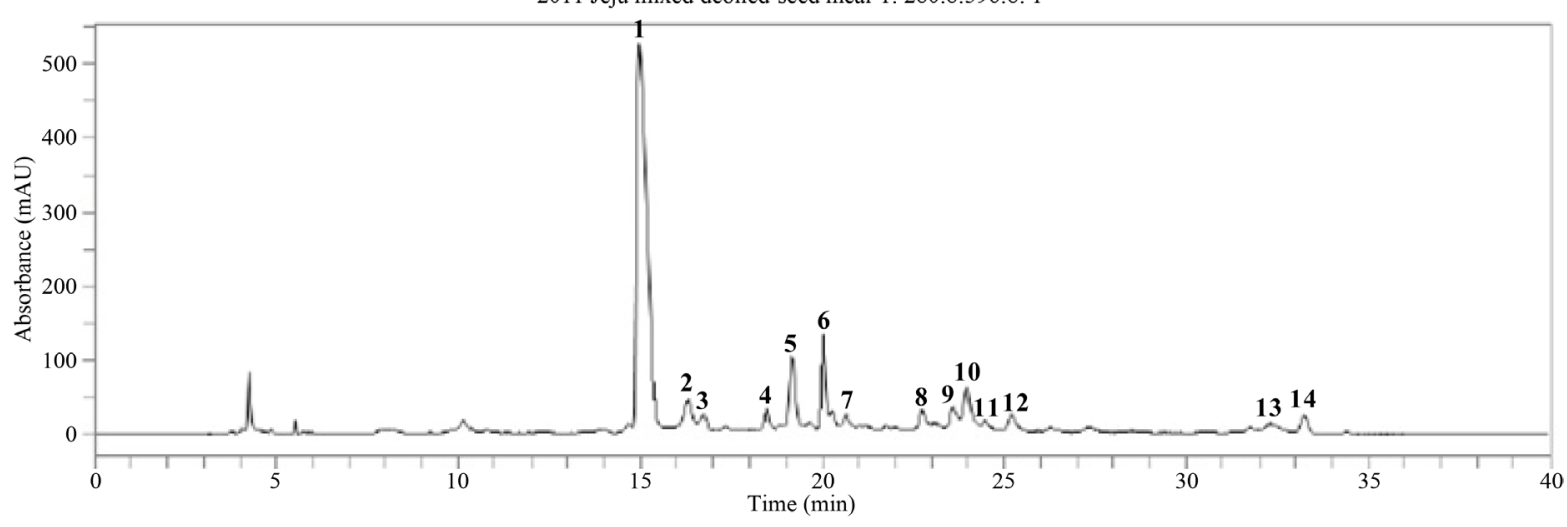

Figure 3. HPLC chromatogram of phenolic compounds in 2011 Jeju mixed rapeseed meal. 
(especially peak 9) but kaempferol molecular weight was not detected in them. Thus the analysis using acid hydrolysis treatment was needed in order to confirm the unknown compounds.

\subsection{Quantification of Phenolic Compounds by HPLC Analysis}

The kaempferol and sinapine was used for quantification of phenolic compounds as external standard in rapeseed meal. The contents of phenolic compounds in rapeseed meal are shown in Table 2. Total phenolic compound content of 2014 Jeju local cultivar was the highest (63.95) and 2012 "Sunmang” was the lowest (45.78 $\mathrm{mg} / \mathrm{g}$ dry weight, DW) but there is little difference of contents in each sample.

Sinapine and 1,2-di-O-sinapoyl-gentiobiose was predominant from the quantified compounds. Sinapine, one of main phenolic compounds was contained wide-ranging amounts in rapeseed meal, with levels in the following order: 2014 Jeju local cultivar $(52.24)>2014$ Import (46.65) > 2011 Jeju local cultivar (41.43) > 2011 “Sunmang” (36.48) > 2012 Jeju local cultivar (34.59) > 2013 “Sunmang” (32.79) > 2012 “Sunmang” (29.74 mg/g DW). Except 2014 samples revealed highest contents, Jeju local cultivar has more amount of sinapine than "Sunmang" in each year. However total kaempferol compounds, sum of kaempferol-3-O-sinapoyl-sophoroside7-O-glucoside, kaempferol-3-O- $\beta$-sophoroside, and kaempferol-sinapoyl-tri-hexoside was not detected with the same tendency. Total kaempferol content was higher in "Sunmang”. On the other hand, the contents of feruloyl choline and cyclic spermidine-alkaloid were so ambiguous that there were did not reveal any tendency, whereas Oskoueian et al. (2011) reported gallic and syringic acids as phenolic acids and apigenin, kaempferol and naringenin as flavonoids in the rapeseed meal [8].

[17] [18] reported that sinapine has anti-nutrition effects such as bitter, sour, astringency for non-ruminant animals. However [19] reported that, sinapine has beneficial effects because of the chemo-preventive, anti-tumor, anti-oxidant, and anti-mutagenic effects. Concretely, sinapine can be used as an active compound to enhance the

Table 2. Phenolic compound contents (mg/g dry wt.) in rapeseed meals $(n=3)$.

\begin{tabular}{|c|c|c|c|c|c|c|c|c|}
\hline \multirow{2}{*}{ No. ${ }^{a}$} & \multirow[b]{2}{*}{ Trivial names } & \multicolumn{2}{|c|}{2011} & \multicolumn{2}{|c|}{2012} & \multirow{2}{*}{$\begin{array}{c}2013 \\
\text { "Sunmang” }\end{array}$} & \multicolumn{2}{|c|}{2014} \\
\hline & & $\begin{array}{l}\text { Jeju local } \\
\text { cultivar }\end{array}$ & “Sunmang” & $\begin{array}{l}\text { Jeju local } \\
\text { cultivar }\end{array}$ & "Sunmang" & & $\begin{array}{l}\text { Jeju local } \\
\text { cultivar }\end{array}$ & Imported \\
\hline 1 & Sinapine & $41.43 \pm 2.60$ & $36.48 \pm 1.82$ & $34.59 \pm 6.05$ & 29.74 & 32.79 & 52.24 & $46.65 \pm 1.13$ \\
\hline 2 & Sinapine(4-O-8')guaiacyl & $1.05 \pm 0.20$ & $0.85 \pm 0.12$ & $0.69 \pm 0.32$ & $0.62 \pm 0.11$ & $0.62 \pm 0.15$ & $0.59 \pm 0.20$ & $2.28 \pm 0.14$ \\
\hline 3 & Feruloyl choline(4-O-8')guaiacyl & $0.63 \pm 0.04$ & $0.61 \pm 0.06$ & $0.39 \pm 0.18$ & $0.69 \pm 0.14$ & $0.77 \pm 0.07$ & $0.07 \pm 0.06$ & $0.83 \pm 0.24$ \\
\hline 4 & $\begin{array}{l}\text { Kaempferol-3-O-sinapoyl- } \\
\text { sophoroside-7-O-glucoside }^{*}\end{array}$ & $0.09 \pm 0.02$ & $0.06 \pm 0.01$ & $0.04 \pm 0.03$ & $0.07 \pm 0.01$ & $0.08 \pm 0.00$ & $0.84 \pm 0.22$ & $0.24 \pm 0.24$ \\
\hline 5 & Kaempferol-3-O- $\beta$-sophoroside ${ }^{*}$ & $0.70 \pm 0.03$ & $0.98 \pm 0.11$ & $0.58 \pm 0.06$ & $0.82 \pm 0.13$ & $1.07 \pm 0.07$ & $0.25 \pm 0.15$ & $0.59 \pm 0.48$ \\
\hline 6 & Unknown-1 & $1.45 \pm 1.26$ & $\mathrm{ND}^{\mathrm{b}}$ & $0.11 \pm 0.10$ & $0.21 \pm 0.03$ & $0.27 \pm 0.04$ & $0.83 \pm 0.48$ & $0.14 \pm 0.12$ \\
\hline 7 & Cyclic spermidine-alkaloid & $0.40 \pm 0.04$ & $0.40 \pm 0.10$ & $0.41 \pm 0.06$ & $0.38 \pm 0.06$ & $0.44 \pm 0.07$ & $0.69 \pm 0.35$ & ND \\
\hline 8 & Feruloyl choline(5-8')guaiacyl & $0.60 \pm 0.10$ & $0.85 \pm 0.06$ & $0.47 \pm 0.16$ & $0.56 \pm 0.20$ & $1.24 \pm 0.13$ & $0.42 \pm 0.03$ & $0.12 \pm 0.10$ \\
\hline 9 & Kaempferol-sinapoyl-tri hexoside ${ }^{*}$ & $0.41 \pm 0.02$ & $0.60 \pm 0.04$ & $0.22 \pm 0.16$ & $0.43 \pm 0.07$ & $1.00 \pm 0.03$ & $0.34 \pm 0.04$ & $0.16 \pm 0.00$ \\
\hline 10 & 1,2-Di-O-sinapoylgentiobiose & $4.28 \pm 0.34$ & $5.47 \pm 0.29$ & $2.65 \pm 1.55$ & $3.80 \pm 0.59$ & $6.63 \pm 3.03$ & $5.13 \pm 1.48$ & $1.19 \pm 0.06$ \\
\hline 11 & 1,2-Di-O-sinapoylglucose & $0.32=$ & 0.12 & $0.03 \pm$ & $0.07 \pm$ & $0.42 \pm 0.03$ & ND & ND \\
\hline 12 & $\begin{array}{l}\text { Feruloyl choline(4-O-8')guaiacyl- } \\
\text { di-sinapoyl }\end{array}$ & $0.65 \pm 0.04$ & $0.72 \pm 0.03$ & $0.60 \pm 0.10$ & $0.40 \pm 0.05$ & $0.44 \pm 0.04$ & ND & ND \\
\hline 13 & Unknown-2 & $0.29 \pm 0.50$ & $0.00 \pm 0.00$ & $0.01 \pm 0.02$ & $0.04 \pm 0.06$ & ND & $1.69 \pm 0.24$ & $1.01 \pm 0.15$ \\
\hline 14 & Sinapine(4-O-8')guaiacyl-di-sinapoyl & $0.64 \pm 0.03$ & $0.96 \pm 0.04$ & $0.39 \pm 0.10$ & $0.67 \pm 0.13$ & $0.02 \pm 0.03$ & $0.87 \pm 0.25$ & $1.10 \pm 0.34$ \\
\hline Total & & $52.95 \pm 4.77$ & $48.10 \pm 2.35$ & $41.18 \pm 7.94$ & $38.50 \pm 6.2$ & $45.78 \pm 4.3$ & 63.9 & $54.20 \pm 2.41$ \\
\hline
\end{tabular}

${ }^{\mathrm{a}}$ No., the elution order of phenolics by HPLC analysis; ${ }^{\mathrm{b}} \mathrm{ND}$, not detected; ${ }^{*}$ quantified with kaempferol standard, but the others with sinapine standard. Note: In 2013, Jeju local cultivar is not cultivated and imported sample was cultivated in India. 

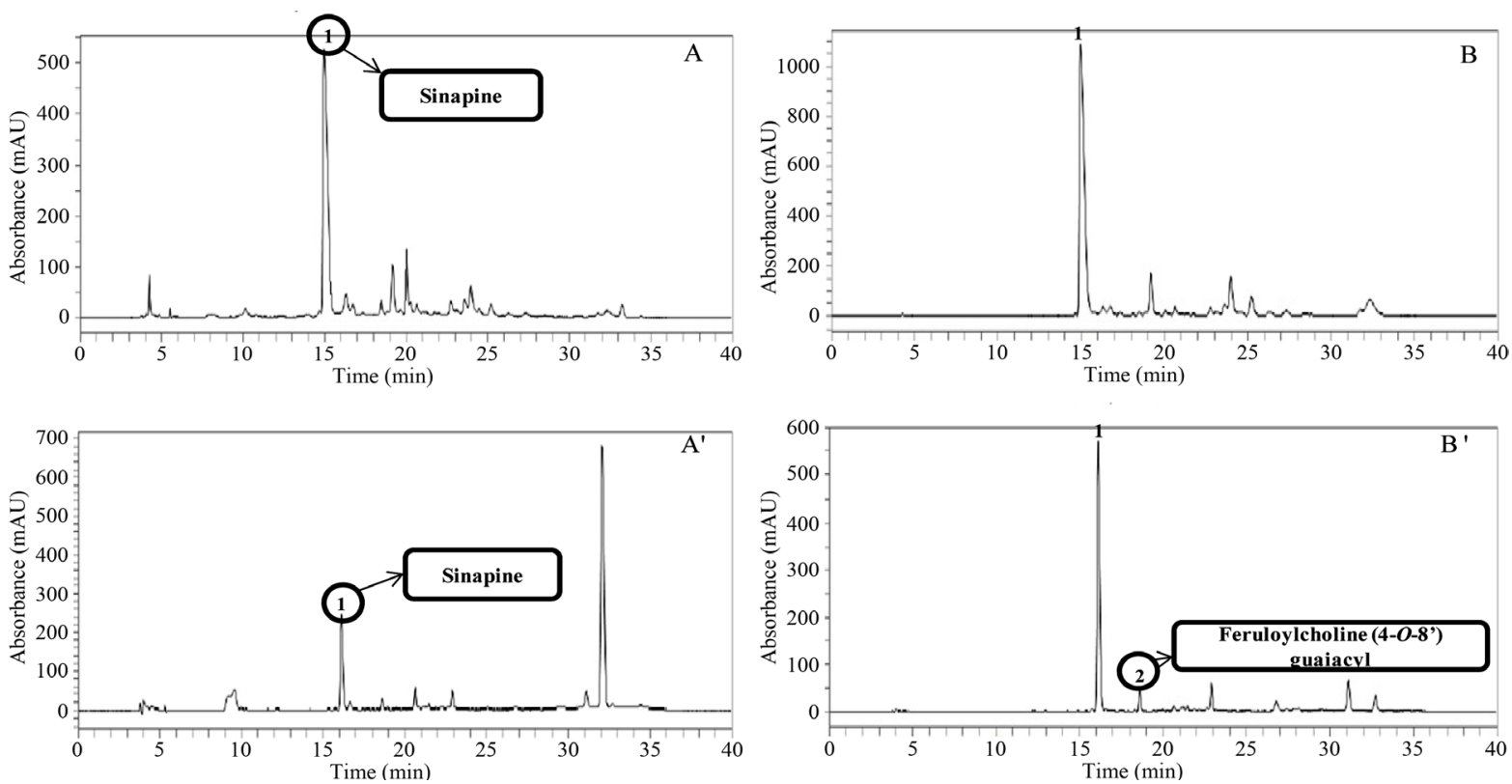

*Peak 1 and 2 were identified by LC-MS analysis.

Figure 4. The comparison of HPLC chromatogram of EII-B (sample:acid = 1:2) in 2011 Jeju mixed meal; A: before acid treatment at $280 \mathrm{~nm}, \mathrm{~B}$ : at350 nm, A': after acid treatment at $280 \mathrm{~nm}, \mathrm{~B}^{\prime}$ : at $350 \mathrm{~nm}$.

effects of doxorubicin used for chemotherapy on cancer. Therefore, sinapine has been attracted researchers by its applications. Kaempferol is one of the flavonol belonged to flavonoids. Flavonoid compounds also have pharmacological properties such as anti-oxidative, anti-allergic, anti-inflammatory, anti-diabetic, hepato- and gastroprotective, anti-viral, and anti-neoplastic activities [11].

\subsection{The Analysis of Rapeseed Meal under Acid Hydrolysis Treatment}

Acid hydrolysis treatment was done to identify the unknown phenolic compounds present in the rapeseed meal. To confirm the unknown compounds (peak 6 and 13) acid hydrolysis treatment was conducted by various extraction methods. Extraction II was selected for acid hydrolysis because the peaks pattern of the extraction II was simpler and separated more clearly and the differences between extraction I and non-acid hydrolysis treatment samples were not significant. LC-MS analysis was performed to confirm what the peaks of HPLC chromatogram were exactly using EII-B that presented most clear peaks among Extraction II. Sinapine (310/251/175) and feruloyl choline(4-O-8)guaiacyl (mass spectra; 476/417/221/145) were detected by LC-MS analysis. However the mass spectra of other peaks were detected with different aspects from non-acid hydrolysis treatment samples, and it was hard to determine that they were certain compounds (Figure 4). That reasons were able to find from analysis data of sinapine. The content of sinapine was expected to increase after acid treatments because many compounds including sinapine have sinapoyl moiety in their structure but the content were rather decreased in fact. Sinapine seems to be decomposed by high concentration of acid. Thus proper ratio of the samples to the acid will be needed for the accurate results of phenolic compound aglycone in further research.

\section{Conclusion}

Twelve phenolic compounds and two unknown compounds in rapeseed meal were identified by LC/MS/MS system at 280 and $350 \mathrm{~nm}$. Cyclic spermidine-alkaloid, feruloyl choline, kaempferol, and sinapine were identified as the main phenolic compounds in LC-MS data. The feruloyl choline has very similar structure with sinapine like Figure 5 [20]. Sinapine was detected with largest amounts (mean 79\%), and the other compounds have just slight differences on each. The quantification and acid hydrolysis treatment would be provided for utilization of rapeseed meal not only for feed stocks or fertilizer but also cosmetic industries or health functional food for human such as protein beverage and biscuit [9]. Furthermore, these utilizations can be developed for bioenergy industry as reducer of cost of the bio-energy products. 


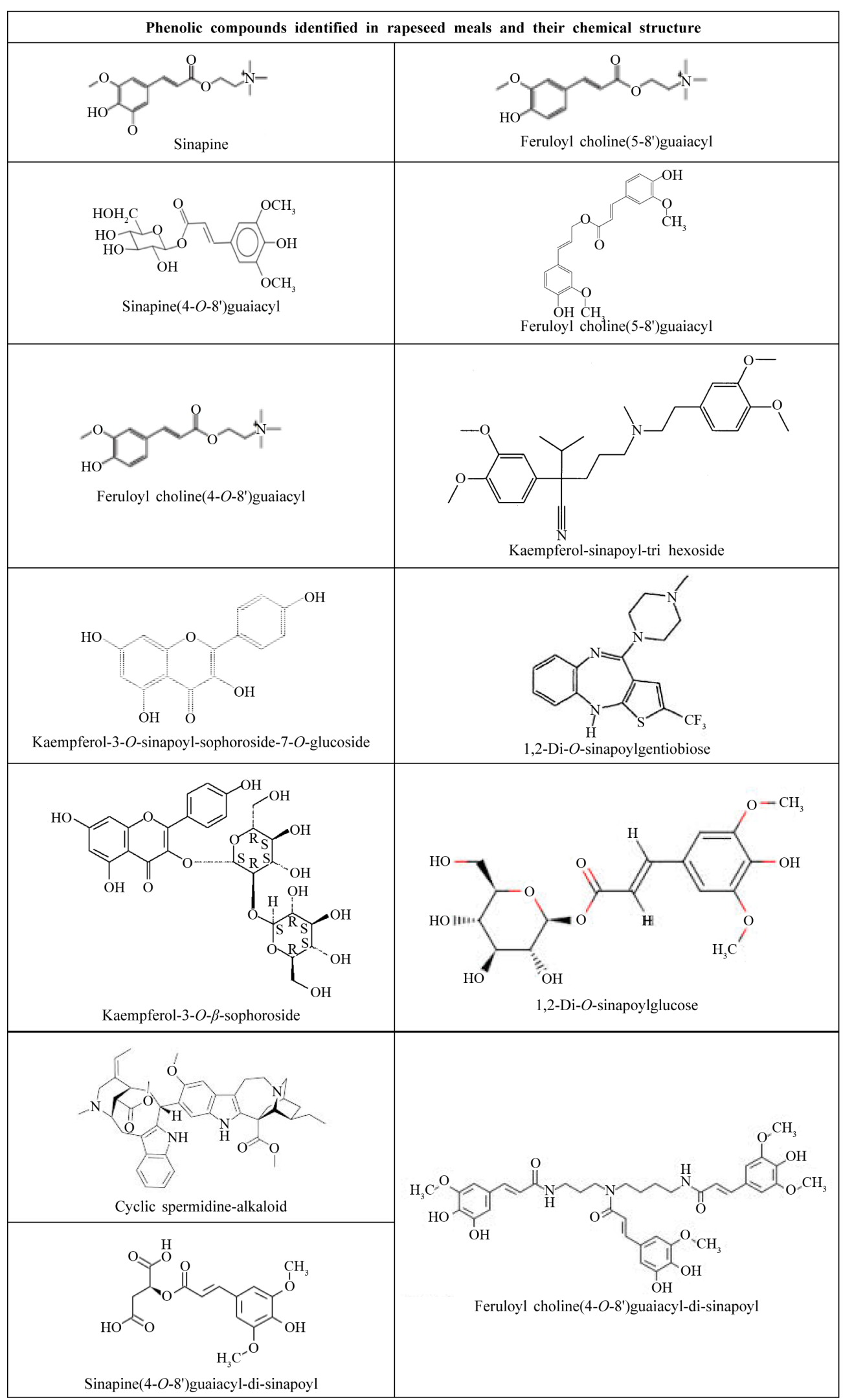

Figure 5. Chemical structure of main phenolic compounds in rapeseed meal. 


\section{Acknowledgements}

This work was supported by iPETs (Korea Institute of Planning and Evaluation for Technology in Food, Agriculture, Forestry, and Fisheries), Republic of Korea (Grant number 409164-03).

\section{References}

[1] Food and Agriculture Organization of the United Nations (2013) FAO Statistic Division. http://faostat.fao.org/site/567/DesktopDefault.aspx?\%20PageID=567\#ancor

[2] Choi, E.-H., Lee, S.-J. and Cho, Y.-S. (2011) Economic Evaluation of Rape Cultivation Using a Survey for Participants on a Pilot Project. Korean Journal of Organic Agriculture, 3, 329-341.

[3] Bae, J.H. (2006) Adoption Forecasts of Bio-Fuel and Analysis of Social Costs and Social Benefits. Occasional Reports, 2006-04, Korean Energy Economics Institute, Ulsan.

[4] Lee, M.-K., Arasu, M.V., Chun, J.H., Seo, J.M., Lee, K.-T., Hong, S.-T., Kim, I.H., Lee, Y.-H., Jang Y.-S. and Kim S.-J. (2013) Identification and Quantification of Glucosinolates in Rapeseed (Brassica napus L.) Sprouts Cultivated under Dark and Light Conditions. Korean Journal of Environmental Agriculture, 32, 315-322. http://dx.doi.org/10.5338/KJEA.2013.32.4.315

[5] Jeong, H.-S., Kim, H.-Y., Ahn, S.H., Oh, S.C., Yang, I. and Choi, I.-G. (2011) Extraction of Liberated Reducing Sugars from Rapeseed Cake via Acid and Alkali Treatments. Journal of the Korean Society of Food Science and Nutrition, 40, 1575-1581. http://dx.doi.org/10.3746/jkfn.2011.40.11.1575

[6] Miean, K.H. and Mohamed, S. (2001) Flavonoid (Myricetin, Quercetin, Kaempferol, Luteolin, and Apigenin) Content of Edible Tropical Plants. Journal of Agricultural and Food Chemistry, 49, 3106-3112. http://dx.doi.org/10.1021/jf000892m

[7] Cartea, M.E., Francisco, M., Soengas, P. and Velascv, P. (2011) Phenolic Compounds in Brassica Vegetables. Molecules, 16, 251-280. http://dx.doi.org/10.3390/molecules16010251

[8] Oskoueian, E., Abdullah, N., Hendra, R. and Karimi, E. (2011) Bioactive Compounds, Antioxidant, Xanthine Oxidase Inhibitory, Tyrosinase Inhibitory and Anti-Inflammatory Activities of Selected Agro-Industrial By-Products. International Journal of Molecular Sciences, 12, 8610-8625. http://dx.doi.org/10.3390/ijms12128610

[9] Bell, J.M. (1984) Nutrients and Toxicants in Rapeseed Meal: A Review. Journal of Animal Science, 58, 996-1010.

[10] Pérez-Gregorio, R.M., García-Falcón, M.S., Simal-Gándara, J., Rodrigues, A.S. and Almeida, D.P.F. (2010) Identification and Quantification of Flavonoids in Traditional Cultivars of Red and White Onions at Harvest. Journal of Food Composition and Analysis, 23, 592-598. http://dx.doi.org/10.1016/j.jfca.2009.08.013

[11] Suzuki, T., Kim, S.-J., Takigawa, S., Mukasa, Y., Hashimoto, N., Saito, K., Noda, T., Matsuura-Endo, C., Zaidul, I.S.M. and Yamauchi, H. (2007) Changes in Rutin Concentration and Flavonol-3-Glucosidase Activity during Seedling Growth in Tartary Buckwheat (Fagopyrum tataricum Gaertn.). Canadian Journal of Plant Science, 87, 83-87. http://dx.doi.org/10.4141/P05-151

[12] Kathleen, C., Baumert, A., Nimtz, M., Milkowski, C. and Strack, D. (2008) Role of a GDSL Lipase-Like Protein as Sinapine Esterase in Brassicaceae. The Plant Journal, 53, 802-813.

http://dx.doi.org/10.1111/j.1365-313X.2007.03374.x

[13] Husken, A., Baumert, A., Milkowski, C., Becker, H.C., Strack, D. and Mollers, C. (2005) Resveratrol Glucoside (Piceid) Synthesis in Seeds of Transgenic Oilseed Rape (Brassica napus L.). Theoritical Applied Genetics, 111, 15531562. http://dx.doi.org/10.1007/s00122-005-0085-1

[14] Wilson, K.E., Wilson, M.I. and Greenberg, B.M. (1998) Identification of the Flavonoid Glycosides That Accumulate in Brassica napus L. cv. Topas Specifically in Response to Ultraviolet B Radiation. Photochemistry and Photobiology, 67, 547-553. http://dx.doi.org/10.1111/j.1751-1097.1998.tb09092.x

[15] Christoph, B., Roepenack-Lahaye, E.V., Schmidt, J., Clemensc, S. and Scheela, D. (2008) Analysis of Phenolic Choline Esters from Seeds of Arabidopsis thaliana and Brassica napus by Capillary Liquid Chromatography/Electrospray Tandem Mass Spectrometry. Journal of Mass Spectrometry, 44, 466-476. http://dx.doi.org/10.1002/jms.1522

[16] Bathide, A., Marnet, N., Gautier, V., Maia-Grondard, A., Leprince, F.-O., Renard, M., Guyot, S., Nesi, N. and Routaboul, J.-M. (2010) A Detailed Survey of Seed Coat Flavonoids in Developing Seeds of Brassica napus L. Journal of Agricultural and Food Chemistry, 58, 6246-6256. http://dx.doi.org/10.1021/jf903619v

[17] Qiao, H. and Classen, H.L. (2003) Nutritional and Physiological Effects of Rapeseed Meal Sinapine in Broiler Chickens and Its Metabolism in the Digestive Tract. Journal of the Science of Food and Agriculture, 83, 1430-1438. http://dx.doi.org/10.1002/jsfa.1559

[18] McFadden, A. and Mailer, R.J. (2003) Sinapine in Australian Canola. In: 13th Biennial Australian Research Assembly on Brassicas, Tamworth, NSW, 96-98. 
[19] Guo, Y., An H., Feng, L., Liu Q., Wang, S. and Zhang, T. (2014) Sinapine as an Active Compound for Inhibiting the Proliferation of Caco-2 Cells via Down Regulation of P-Glycoprotein. Food and Chemical Toxicology, 67, 187-192. http://dx.doi.org/10.1016/j.fct.2014.02.035

[20] Yao, L.H., Jiang, Y.M., Shi, J., Tomas-Barberan, F.A., Datta, N., Singanisong, R. and Chen, S.S. (2004) Flavonoids in Food and Their Health Benefits. Plant Foods for Human Nutrition, 59, 113-122. http://dx.doi.org/10.1007/s11130-004-0049-7 
Scientific Research Publishing (SCIRP) is one of the largest Open Access journal publishers. It is currently publishing more than 200 open access, online, peer-reviewed journals covering a wide range of academic disciplines. SCIRP serves the worldwide academic communities and contributes to the progress and application of science with its publication.

Other selected journals from SCIRP are listed as below. Submit your manuscript to us via either submit@scirp.org or Online Submission Portal.
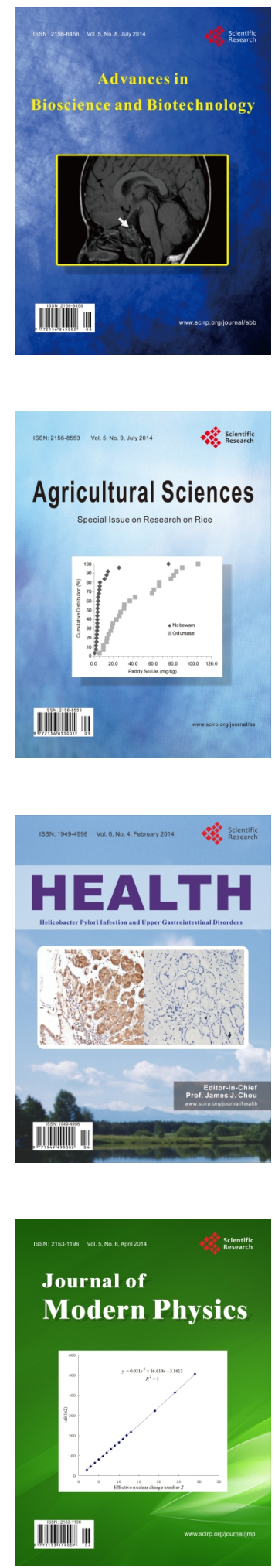
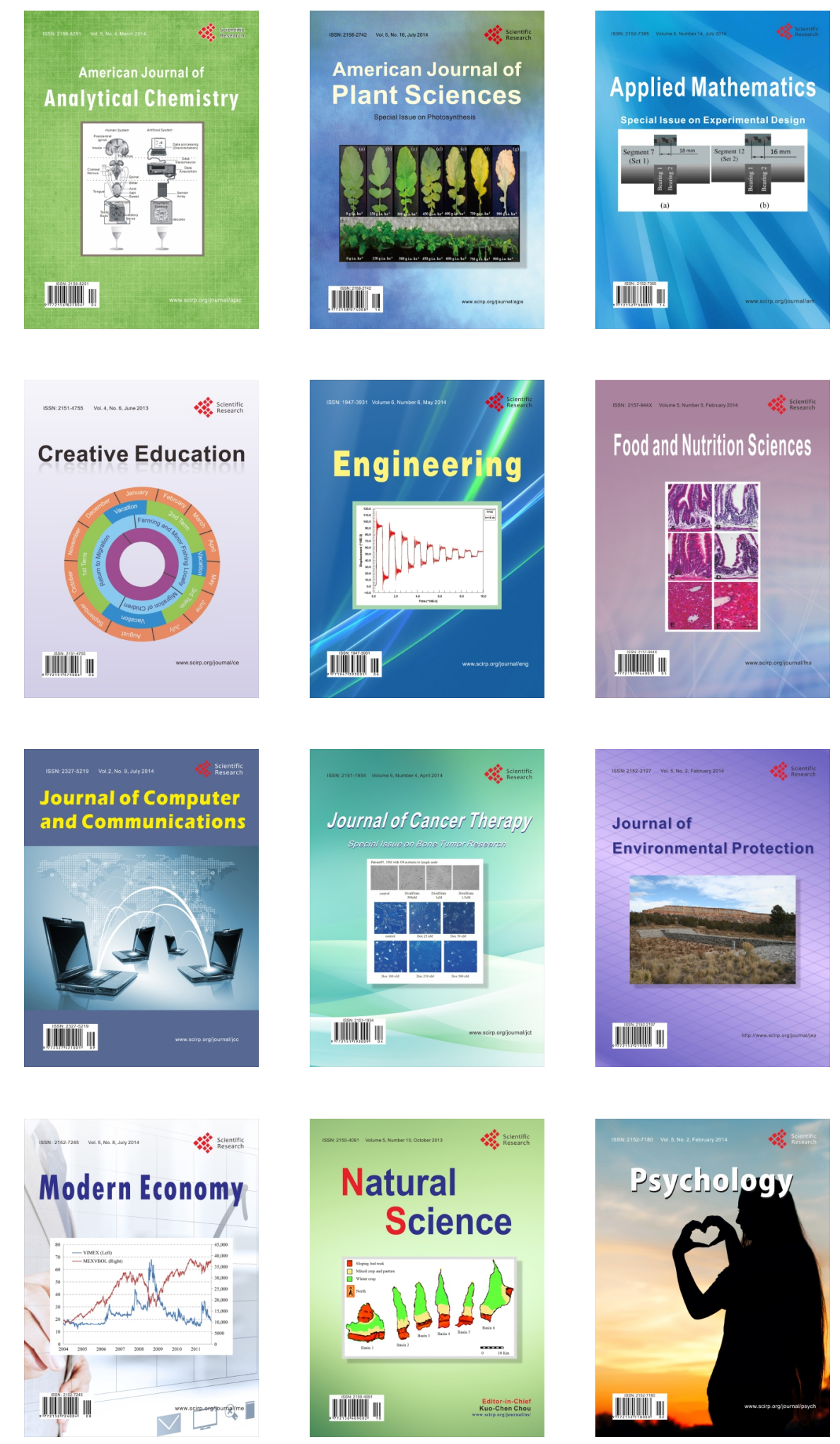